Article

\title{
The Cancer's Margins Project: Access to Knowledge and Its Mobilization by LGBQ/T Cancer Patients
}

\author{
Evan T. Taylor ${ }^{1, *}$, Mary K. Bryson ${ }^{1}$, Lorna Boschman ${ }^{1}$, Tae L. Hart ${ }^{2}$, Jacqueline Gahagan ${ }^{3}$, Geneviève Rail ${ }^{4}$ \\ and Janice Ristock ${ }^{5}$ \\ ${ }^{1}$ Department of Language and Literacy Education, University of British Columbia, Vancouver, BC V6T 1Z2, Canada; \\ E-Mails: e.taylor@alumni.ubc.ca (E.T.T.), mary.bryson@ubc.ca (M.K.B.), lorna@digitalstories.ca (L.B.) \\ 2 Department of Psychology, Ryerson University, Toronto, ON M5B 2K3, Canada; E-Mail: tae.hart@psych.ryerson.ca \\ ${ }^{3}$ School of Health and Human Performance, Dalhousie University, Halifax, NS B3H 4R2, Canada; \\ E-Mail: jacqueline.gahagan@dal.ca \\ ${ }^{4}$ Simone de Beauvoir Institute, Concordia University, Montreal, QC H3G 1M8, Canada; E-Mail: gen.rail@concordia.ca \\ ${ }^{5}$ Department of Women's and Gender Studies, University of Manitoba, Winnipeg, MB R3T 2N2, Canada; \\ E-Mail: janice.ristock@umanitoba.ca \\ * Corresponding author
}

Submitted: 17 August 2018 | Accepted: 19 October 2018 | Published: 5 February 2019

\begin{abstract}
Sexual and/or gender minority populations (LGBQ/T) have particular cancer risks, lower involvement in cancer screening, and experience barriers in communication with healthcare providers. All of these factors increase the probability of health decisions linked with poor outcomes that include higher levels of cancer mortality. Persistent discrimination against, and stigmatization of, LGBQ/T people is reflected in sparse medical curriculum addressing LGBQ/T communities. Marginalization makes $L G B Q / T$ persons particularly reliant on knowledge derived from online networks and mainstream media sources. In what is likely the first nationally-funded and nation-wide study of LGBQ/T experiences of cancer, the Cancer's Margins project (www.lgbtcancer.ca) conducted face-to-face interviews with 81 sexual and/or gender minority patients diagnosed and treated for breast and/or gynecological cancer in five Canadian provinces and the San Francisco Bay area (US). With specific attention to knowledge access, sharing, and mobilization, our objective was to document and analyze complex intersectional relationships between marginalization, gender and sexuality, and cancer health decision-making and care experiences. Findings indicate that cancer care knowledge in online environments is shaped by cisnormative and heteronormative narratives. Cancer knowledge and support environments need, by contrast, to be designed by taking into account intersectionally diverse models of minority identities and communities.
\end{abstract}

\section{Keywords}

biographical knowledge; biomedical knowledge; cancer; cancer care; gender; health disparities; health equity; information access; LGBT health; minority cancer patients; transgender; treatment

\section{Issue}

This article is part of the issue "Communicating on/with Minorities", edited by Leen d'Haenens and Willem Joris (KU Leuven, Belgium).

(C) 2019 by the authors; licensee Cogitatio (Lisbon, Portugal). This article is licensed under a Creative Commons Attribution 4.0 International License (CC BY). 


\section{Introduction}

The design of culturally competent and medically effective cancer treatment and care is dependent upon understanding both sexual diversity and gender diversity as key elements of the body of knowledge that shapes minority population health. Research has revealed a number of cancer health disparities for members of sexual and/or gender minority populations ( $(\mathrm{LBQ} / \mathrm{T})^{1}$, including: avoidance of cancer screening, longer time between followup appointments, less screening reliability, issues with service provision and refusal, poor healthcare provider communication, and lower self-rated health (Boehmer, Glickman, Winter, \& Clark, 2013; Burkhalter et al., 2016; Jabson, Farmer, \& Bowen, 2015; Kamen, SmithStoner, Heckler, Flannery, \& Margolies, 2015; Peitzmeier, Reisner, Harigopal, \& Potter, 2014; Tabaac, Sutter, Wall, \& Baker, 2018; Taylor \& Bryson, 2016). Recently, there have been calls in the field of oncology for better information about the cancer health experiences of gender and sexual minority populations (Burkhalter et al., 2016; Griggs et al., 2017). Critical perspectives on breast and gynecologic cancer and the organization of health care and knowledge have also prioritized a reorganization and rebranding of these cancers so as to move away from the problematic and reductive categorical representation of these cancers as "women's cancers" (Jain, 2007; Klawiter, 2004; Sulik, 2011; Taylor \& Bryson, 2016).

Recently, the American Society of Clinical Oncology released a position statement outlining the importance of addressing cancer health disparities and the suboptimal care that sexual and/or gender minority patients experience across the cancer trajectory (Griggs et al., 2017). While many cancer care providers have supportive attitudes towards sexual and/or gender minority populations, they lack training and knowledge about the unique health needs of these populations. A recent survey of cancer care providers found that only $47 \%$ of cancer specialists assessed themselves as being well-informed on LGBQ/T health (Tamargo, Quinn, Sanchez, \& Schabath, 2017). Additionally, less than half of cancer specialists correctly answered questions about specific LGBQ/T cancer health needs and disparities: including quality of life and sexual activity, differences in cancer risk profiles, and disclosure and health outcomes (Tamargo et al., 2017).

Medical education and training for providing care to sexual and gender minority populations is woefully inadequate (Banerjee, Walters, Staley, Alexander, \& Parker, 2018; Obedin-Maliver et al., 2011), and results in cancer care providers who are not prepared to treat a wide diversity of sexual and/or gender minority patients (Tamargo et al., 2017). The importance of sexual and gender minority health knowledge among health providers cannot be underestimated as qualitative research has shown that increased LGBQ/T health knowledge is di- rectly associated with increased willingness and capacity to provide culturally competent cancer care (Banerjee et al., 2018). However, the inclusion of sexual and gender diversity in cancer treatment, as well as related knowledge seeking, health communication, and treatment decision-making, remain profoundly under-studied areas of cancer research (Burkhalter et al., 2016; Watters, Harsh, \& Corbett, 2014).

The advent of easily accessible cancer health information online has changed the ways that patients make decisions about their health (Ziebland \& Herxheimer, 2008). However, claims that online access to health knowledge contributes positively to consumer health have been called into question by extensive research evidence of unequal distributions of both health knowledge and access to knowledge (e.g., Bryson \& Stacey, 2013; Jabson, Patterson, \& Kamen, 2017; Newman, Biedrzycki, \& Baum, 2012; Orgad, 2006) that are linked to the lack of "structural competency" that produces population-level marginalization (Donald, Dasgupta, Metzl, \& Eckstrand, 2017; Metzl \& Hansen, 2014). Public access to structurally competent health knowledge for members of minority populations remains an under-researched social determinant of health disparities (Newman et al., 2012). In particular, marginalized patient groups have uneven access to online cancer health knowledge and are excluded from the online knowledge ecologies proliferated by cancer support programs and organizations (Gibson, Lee, \& Crabb, 2016). Conceptualizations of accessing information online as a key component of media literacy include not only the technical skill required to access media, but also a measure of cultural knowledge and competency (Orgad, 2006).

Research has shown that online knowledge seeking can assist patients to become increasingly more informed about their health (Wald, Dube, \& Anthony, 2007). Recent research has confirmed that when patients have a positive relationship with care providers, online health information seeking can improve relationships with providers because it can provide greater opportunities for discussion (Tan \& Goonawardene, 2017). However, additional research on clinical interactions suggests that there are barriers to patient-provider interactions and communications between cancer care providers and sexual and gender minority patients (Agénor, Bailey, Krieger, Austin, \& Gottlieb, 2015; Bryson et al., 2019; Gibson, Radix, Maingi, \& Patel, 2017). Specifically, problematic communication between providers and patients exacerbates already-existing populationbased health disparities. In North America, most cancer care is organized around the model of "shared decision-making", which only works well when there is a strong evidence base to inform care decisions coupled with a high degree of cultural competence that informs patient-provider communication (Grabinski, Myckatyn,

\footnotetext{
${ }^{1}$ Lesbian, Gay, Bisexual, Queer, and Transgender. Our use here of the acronym LGBQ/T is not intended to denote any kind of simplistic or static ontology, experience, or coherency between categories of sexuality and gender and their relation to identity, embodiment, visibility, and group recognition. We acknowledge the subjugatory and liberatory effects of these locationally and discursively situated and highly contestable signifiers.
} 
Lee, Philpott-Streiff, \& Politi, 2018; Kirby et al., 2018). Sexual and/or gender minority cancer patients face a doubled health disparity in terms of, first, having less positive relationships their providers (Boehmer \& Case, 2004; Matthews, Breen, \& Kittiteerasack, 2018) which then, secondarily, prevents them from being able to take advantage of the improved health decision-making that might otherwise result from online health information seeking and subsequent patient-provider interactions.

Quantitative research suggests that LGBQ/T folks are likely to go online to seek health information, and, when seeking health information for themselves and others, have a higher probability of being exposed to incidental health information online than heterosexual populations (Jabson et al., 2017). When sexual and gender minority people are gathering health information online, their risk of being exposed to and utilizing inaccurate health information is increased (Jabson et al., 2017). Therefore, understanding how sexual and/or gender minority people with cancer access, navigate, and coordinate cancer knowledge both online and in face-to-face communication will inform the design of culturally and medically competent web-based information and support systems. No previous research to-date has specifically addressed the need for evidence concerning online knowledge seeking and access by LGBQ/T cancer patients. The Cancer's Margins project directly addresses the need for research concerning LGBQ/T health informatics. The analysis presented here is intended to advance knowledge concerning cancer health knowledge access and the mobilization of support by LGBQ/T people diagnosed with breast and/or gynecologic cancer.

\section{Method}

The design of the Cancer's Margins research methodology is informed by theoretical frameworks from the Social Study of Medicine (SSM) that deploy sociocultural and post-structural approaches to an analysis of subjectivity, the mobilization of knowledge, and experiential narratives of health and wellbeing (e.g., Bryson \& Stacey, 2013; Diedrich, 2007; Mol, 2002). When applied to sexual and gender minority population health issues, SSM methods allow analyses to take into account the subjective experiences of participants as being valuable and credible sources of knowledge, while also simultaneously considering the larger structural and historical contexts shaping those experiences. This analysis of the role of knowledge access in varied discursive contexts pays particular attention to online knowledge ecologies, including in particular, the specific roles of biomedical and biographical knowledge (Bryson et al., 2019) that patients navigate and coordinate in the flux of cancer health decision-making. This analysis seeks to identify both kinds of knowledge and also, the access and mobilization techniques that are typical for sexual and gender minority cancer patients. Where the context of cancer treatment is organized around cisgender and heterosex- ual narratives of treatment and support, the biographical and embodied knowledge of sexual and gender minority patients is discordant relative to the ubiquitous "women's cancer" narratives of femininity, gender, embodiment, identity, and decision-making.

Our analysis asks: What types of knowledge and social support are sexual and/or gender minority breast and gynecologic cancer patients seeking in the multiple contexts of cancer health decision-making, including online and elsewhere? Cancer's Margins also investigates how sexual and gender marginality, both distinctly and intersectionally, discursively and materially shape access to and mobilization of knowledge and support for cancer patients.

Cancer's Margins participants were recruited from urban, suburban, and rural locations in 5 Canadian provinces: British Columbia (BC), Manitoba (MB), Ontario (ON), Quebec (QC), and Nova Scotia (NS). The sample also includes pilot interviews with LGBQ/T people diagnosed and treated for breast and/or gynecologic cancer living in the San Francisco Bay Area (BA). Using non-random, purposive recruitment methods-such as snowball sampling - that are considered optimal for use with "hard-to-reach" populations (Bonevski et al., 2014), a diverse sample of $L G B Q / T$ participants was recruited (see Table 1$)$. The sample $(n=81)$ varied in age, sexual and gender identity, race and ethnicity, dis/ability, socio-economic status, as well as in the type of cancer and stage. Many studies of LGBQ/T health exhibit a problem of unrepresentative samples in terms of race and also, gender diversity (Meyer \& Wilson, 2009). Cancer's Margins' deployment of proactive and focused recruitment practises resulted in a sample that is broadly representative of the Canadian population regarding race and ethnicity (Statistics Canada, 2017). Since there are no national demographic data concerning gender diversity, it is hard to say what a representative sample should look like. Participants were asked directly if they identified as transgender or gender nonconforming in any way; 10 participants answered affirmatively, and 71 participants answered "no". Of the 71 who answered "no" to this question, 31 self-identified as "cisgender" or "woman". The other 38 of the 71 participants (who did not self-identify as transgender or gender nonconforming) nevertheless used a variety of non-normative identity terms to describe their gender (e.g., kinky femme, genderqueer, butch, etc.) that indicated a more complex relationship to gender than what arises in cisgender narratives. The age range of participants was between 33 to 75 years old and all had been diagnosed with and treated for breast and/or gynecologic cancer. Interviews focused on eliciting information about participants' understanding of intersectional elements of their identities and histories, as well as their experiences along the trajectories of cancer care from screening, to diagnosis, treatment, and ongoing surveillance and/or metastatic care, including their access to knowledge and the mobilization of knowledge, as these relate to support net- 
Table 1. Participant demographic table.

\begin{tabular}{|c|c|c|c|c|c|c|c|c|c|}
\hline \multicolumn{6}{|c|}{ Geographic Location } & \multicolumn{4}{|c|}{ Age } \\
\hline$B C: C A$ & MB: $C A$ & $O N: C A$ & $Q C: C A$ & $N S: C A$ & BA: US & $33-46$ & $47-56$ & $57-66$ & $67-75$ \\
\hline 21 & 9 & 23 & 8 & 7 & 13 & 19 & 34 & 21 & 7 \\
\hline
\end{tabular}

Gender: Do you identify as Transgender?

\begin{tabular}{|c|c|c|c|c|c|c|}
\hline Yes: Trans & Yes: GNC & No: Genderqueer & No: Cisgender & Lesbian & Queer & Bisexual \\
\hline 7 & 3 & 38 & 33 & 26 & 46 & 9 \\
\hline
\end{tabular}

\begin{tabular}{cccccc}
\multicolumn{7}{c}{ Race/Ethnicity } \\
\hline Caucasian & Black & Asian & Indigenous & Hispanic & Mixed Race \\
\hline 58 & 3 & 6 & 6 & 3 & 5 \\
\hline
\end{tabular}

\begin{tabular}{|c|c|c|c|c|c|c|c|}
\hline \multicolumn{4}{|c|}{ Cancer: Type } & \multicolumn{4}{|c|}{ Cancer: Stage } \\
\hline Breast & Cervical & Ovarian & Uterine & DCIS/One & Two & Three & Metastatic \\
\hline 51 & 7 & 16 & 13 & 25 & 31 & 15 & 10 \\
\hline
\end{tabular}

works, treatment decision-making, and experiences of care and information seeking. Research ethics approval was received from the research ethics review boards at each of the investigators' home universities.

This qualitative data analysis of Cancer's Margins interview transcripts focuses on participants' experiences with seeking knowledge or support and the knowledge mobilization practices and techniques employed by sexual minority and gender minority cancer patients. Data analysis included the use of MAXQDA qualitative data analysis software to perform the initial coding of all transcripts, as well as the refinement of the coding system for consistent inter-coder reliability across the dataset of 81 transcripts.

\section{Findings}

\section{1. "What it Really Meant, What We're Dealing with":} Patient-Provider Communication, Disclosure, and Online Biomedical Knowledge Seeking by Sexual and/or Gender Minority Cancer Patients

A cancer diagnosis typically precedes an intensive engagement with medical systems and providers. Participant accounts of the complex and laborious coordination of biographical and biomedical knowledge sources during cancer health and treatment decision-making reveal significant use of online knowledge seeking for themselves and for/by people in their support networks. Informational support was a key driver in online knowledge seeking activities. For example, Dana talked about a friend, a primary member of Dana's cancer support net- work and also a sexual minority community member diagnosed with cancer, who provided Dana with research she had done on breast cancer.

"She was on the Internet, and she's a very smart cookie. So she was looking at just about anything she could find, including medical research." Dana (BA, 64, Caucasian, gentlemanly butch, breast cancer) ${ }^{2}$

Many participants reported that both they and their support network members spent more time online subsequent to their cancer diagnoses, and that accessing information online had become a primary source of knowledge. They recalled being online for "many hours", or spending the "whole day online", pointing to a consistently high pattern of Internet use related to cancer diagnosis and treatment decision-making.

"I get on the Internet for many hours every day now." Heather (BA, 54, Caucasian, kinky femme, femme dyke, breast cancer)

"I would always use the Internet for research." Barbara (BA, 54, Caucasian, femme, queer, metastatic breast cancer)

"I would spend a whole day online, looking at things, and then I would get a bit burned out from that. But then I would do it (again) because I would get reassured, by finding out different things, and just knowing what's what, a little bit." Paula (BC, 48, Japanese Canadian, gender nonconforming, queer, breast cancer)

\footnotetext{
${ }^{2}$ The demographic information following each quote from the transcripts includes the participant pseudonym as well as those particular words that each participant used to communicate the specificities of their locations relative to categories of location, age, race and/or ethnicity, modes of gender identification and sexual identification, and type of cancer diagnosis.
} 
"It was like breastcancer.org, the discussion boards on chemotherapy, side effects in treatment kind of things, was like my bible; my go-to. I would go there and read and read and read and read." Holly (BA, 44, Jewish, femme, queer bisexual, breast cancer, BRCA1 gene)

Participation in shared decision-making models is directly affected by the quality of patient-provider communication that, for sexual and gender minority patients, is often encumbered by power differentials between patients and providers and also, by the existence of mistrust and a very high level of vigilance by patients about the possible impacts of disclosure related to either minority sexuality or gender. Additionally, there is a significant impact of the lack of evidence pertaining to LGBQ/T cancer patients on the quality of patient-provider interactions about cancer health decisions. While online information seeking is performed by many cancer patients of all sexualities and genders to seek further clarification of biomedical information, the increased barriers to communication and knowledge access in relation to care providers experienced by sexual and/or gender minority cancer patients makes the use of online resources to make sense of biomedical information all the more crucial as a source of information for cancer health decisionmaking. Gender and sexual minority patients have an already hindered access to knowledge based on barriers present in the patient-provider relationship. Patients who are marginalized in the clinic will seek the information they need from other sources, and the Internet is consistently found to be an increasing source of health knowledge. Participants reported that clarification of medical knowledge took place throughout the trajectory of their cancer experiences and identified the period of diagnosis and staging to be particularly significant.

"It wasn't until I actually saw the pathology readout that I got some of those things explained. And what I did is, I sat there with the pathology report, and an online guide to the pathology 'Your Pathology Report' and tried to sort of match it up." Holly (BA, 44, Jewish, femme, queer bisexual, breast cancer, BRCA1 gene)

"I was wanting to learn more about the stages and the grades of cancer-to try and understand the levels and the scales.... did a bit of research about that, just to understand my (diagnosis)..... th was to explain and to confirm for me what it really meant." Diane (NS, 39, Caucasian, femme, lesbian, uterine cancer)

"Then (I) started going on the Internet too. Started looking at things. I think (I) just started with basically a Google search. You could go on to some of the medical sites; it was here in Canada....The one I found was actually very good because it explained and showed diagrams and explained all the pieces of it. So it was like, 'Oh okay, so that's what it is. And that's what we're dealing with'." Donna (MB, 53, Caucasian, lesbian woman, breast cancer)

Disclosure of sexual and/or gender minority identity to health care providers is a key communication issue and is highly related to quality of healthcare outcomes generally, and specifically, cancer health outcomes and quality of life and wellness measures. Cancer care providers frequently neglect to ask about the sexual and gender identities of their patients, which constitutes an increased barrier to communication and rapport, inflating the risk of disparities in care for LGBQ/T cancer patients. With disclosure being directly linked to better experiences of cancer care and wellbeing (Kamen et al., 2015), it is significant to note that Cancer's Margins participants consistently reported that they actively managed the disclosure of their sexual and gender identities-often hiding their identities in online environments-in order to access support and information in cisnormative and heteronormative online environments.

"I don't talk about it. I'm totally closeted....I keep it undercover in the online group." Barbara (BA, 54, Caucasian, femme, queer, metastatic breast cancer)

Our findings reveal that sexual and gender minority cancer patients perform significant cancer health knowledge seeking online and suggest that web-based knowledge and support environments could be an effective and efficient way to access both biomedical and biographical cancer health knowledge and support for LGBQ/T patient populations by reducing the amount of navigation and coordination that patients need to do to sort through the support and information online to find what is relative to them. Online resources that provide information specifically for LGBQ/T cancer patients may partially alleviate the additional knowledge seeking burden on these marginalized patients as a result of barriers in their communication and relationships with care providers.

\section{2. "It Didn't Work for Me": Cisnormativity and Heteronormativity as Barriers to Online Knowledge Access and Mobilization}

Given the lack of competence in working with sexual and gender minority patients that has been assessed in cancer care providers, marginalized patients are positioned to "manage the unmanageable" (Mason, 2001, p. 39) by being tasked with finding a provider who is both medically competent and culturally competent. Participants reported that they specifically went online to find knowledge and information about providers who were, in some way, reputed to be willing, experienced, and/or "friendly" in working with sexual and gender minorities and used this information to make decisions about providers. 
"They had a list of (care) providers that are quote unquote 'LGBT friendly'." Angela (BA, 33, Caucasian, queer, dyke, breast cancer, uterine cancer)

As previous research on online cancer resources has noted (Gibson et al., 2016), the marginalization of sexual and gender minority populations compels many patients to seek out culturally competent providers - with no suggestion as to how to accomplish this-placing the responsibility to resist the cisnormative and heteronormative narratives of cancer care onto individual patients.

Sexual and gender minority cancer patients are highly attuned to find biographically relevant knowledge as a key element of the navigation of online knowledge and support. Cancer's Margins interviewees talked about what they noticed online and how they made decisions about whether or not a particular resource was a good fit. They paid attention to the language and topics used in order to assess the level of LGBQ/T inclusion in a wide array of knowledge ecologies.

"Really early on in my online reading, I realized that lots of people were praying for other people. And lots of people had a DH ("darling husband"). And nobody in the general threads said anything about my DW ("darling wife"). There is a thread for lesbians. I found it strangely underdeveloped. It didn't work for me. I thought, 'Boy, it's not fair for me to just read and read and not participate.....And then I thought 'I'm not comfortable being out on this. And I can't imagine being in. So I'm not going to join'." Holly (BA, 44, Jewish, femme, queer bisexual, breast cancer, BRCA1 gene)

Ethnographic accounts of cancer care systems and marginalized cancer patient experiences have pointed to heteronormative and cisnormative knowledge systems as organizing factors in cancer care (Jain, 2007; Klawiter, 2004). The Cancer's Margins project findings have also detailed deleterious effects of cisnormativity on trans and gender nonconforming cancer patients (Bryson et al., 2019; Taylor \& Bryson, 2016). Participants described at length how cisnormative and heteronormative knowledge systems influenced many aspects of their care, such as support access and patient-provider relationships, and led to substandard care and a lack of attention to the specific aspects of patients' experiences that were key aspects of minority sexuality and/or gender identity.

"The thing that was just blatantly absent was the queer element. Nobody talked about it. It was completely absent from discussion on the boards." Serena (BC, 39, Caucasian, punk femme, bisexual, breast cancer)

"I went online and I started to do research....It's all very mainstream" Shirley (BC, 52, Jewish, femme, dyke, cervical cancer)
"I didn't find information that focused on lesbian women who had cancer. Absolutely nothing. I would have liked it, but I didn't find anything like that." Olivia (QC, 60, Caucasian, lesbian woman, breast cancer)

The pink ribbon branding of breast cancer support sites is also part of the systemic barriers for sexual and gender minority patients seeking cancer information. Participants reflected that the feminized gendering of cancer websites was a barrier to their engagement and inclusion in accessing knowledge or support online. The branding of a website that uses the pink ribbon approach to breast cancer was interpreted by LGBQ/T participants as an effect of heteronormative and cisnormative narratives.

"I was opposed to the pink ribbon effect that was a major marketing tool for non-profit sites focused on women and cancer." Olivia (QC, 60, Caucasian, lesbian woman, breast cancer)

Our analysis revealed that the cisnormative and heteronormative narratives that inform patient experiences of biomedical care also shape the representation of online biomedical information, as well as support websites. The cisnormative and heteronormative narratives of cancer that are invoked on cancer websites were perceived as a barrier to online engagement by interview participants who were seeking inclusive locales for knowledge and support.

\section{3. "Talking on Different Wavelengths": Gender Minority Patients, Shared Decision-Making, and Structural Competency}

We have previously reported on the alarming lack of coordination between gender affirming care and cancer care for gender minority patients (Taylor \& Bryson, 2016). In the analysis reported here, gender minority patients reported that online cancer knowledge was uncoordinated with knowledge concerning gender affirming care. Despite extensive knowledge seeking, none of the transgender participants in the Cancer's Margins study reported accessing any cancer health information or support online that was specific to gender minority populations and many indicated that they were lacking support.

"I spent a lot of time trying to find information about (transgender cancer patients online). Because the first thing, when you tell people you have cancer, and you're trans, is "Oh, it is because of your hormones?" A lot of people say that, which drives me nuts. Like you did this to yourself. You know, there's zillions of trans people and not all of them have cancer! I don't even think there's any studies to show that the rates are higher. I was looking at all the possibilities and I didn't really find any information." John (ON, 33, Asian-Canadian, trans man, queer, breast cancer) 
While most of the transgender participants reported accessing some form of gender affirming care, their cancer care did not in any way take this into account. The lack of information at the intersection of cancer health and gender affirming medical care prevents the meaningful integration of medical knowledge and culturally competent care for gender minority cancer patients and creates an enormous barrier to informed and shared decision-making. Patient-provider communication was completely stymied by this lack in structural competency for gender minority patients.

"I keep running across that: 'I'm the unique patient that they don't have any experience with'.....And you know, specialists at the best of times don't really want to get their information from their patients. They don't want to be educated by their patients because it tips the power imbalance, doesn't it?" James (BC, 58, Caucasian, trans man, bisexual, cervical cancer)

Particularly in relation to hormone administration, oncologists were unaware of the benefits to the trans cancer patient that would accrue from coordinated care regimens. When attempting to engage in shared decisionmaking with their care providers, gender minority participants were keenly aware of the lack of available biomedical information about their gender affirming cancer health needs.

"There's a growing awareness that lesbian and gay people have specialized needs (but) trans healthcare is way, way out there. Even though I think that would be easier to address medically, because there is actually a biological (context)....But, it's so far from people's minds...they couldn't advise me one way or the other. (My doctor) said, 'You know, there aren't really numbers to support, in your case, if it's going to help you or not'.... But, there's no shortage of information for biological women who are female identified to access information." John (ON, 33, Asian-Canadian, trans man, queer, breast cancer)

When gender minority cancer patients seek out cancer health information online, they often attempt to coordinate additional bodies of knowledge, such as biomedical knowledge about gender affirming care. However, neither patients nor their providers have the knowledge needed for decision-making about the overlaps in cancer risk, cancer treatment, and gender affirming surgical and hormonal care. John directly described how the lack of coordination of online gender minority health knowledge and cancer health knowledge created a barrier in his communication and his informed and shared decision-making with his surgeon:

"There's certainly no trans stuff, not even online, that I could find or that was what I needed.... had said to (my surgeon), "In the time that I've been waiting,
I've been doing a lot of research online....Are there sources of information that are better than others, in your experience?.' He said "Google breast cancer." I was like, 'Oh my friend, we are talking on different wavelengths here'. So I realized that he wasn't a source of information. I was waiting for my surgery, and he didn't hook me up with any resources or anything." John (ON, 33, Asian-Canadian, trans man, queer, breast cancer)

Despite, or perhaps as a result of, the lack of gender minority specific information and support online, gender minority participants had clear and direct ideas about how to make online cancer knowledge and support websites more available and accessible to marginalized communities.

"Each page that you go to is clean looking. In other words, don't have a lot of stuff on each page. Have it so the type is fairly large. And don't put backgrounds like, black with blue lettering. I've seen that on websites. Terrible. You can't read the damn thing, right? For people who are visually impaired, you have to have it really good, right? Make a site that you can also access for deaf people-signing the information. If you put people in, of course, a wide variety of people-not just a bunch of white folks, which drives me crazy when I go to websites. I also want to see culturally-specific information as well. In terms of the website, you just gotta have lots of good information." Jolene (ON, 59, Caucasian, genderfluid, transgender, queer, metastatic breast cancer)

Cancer support and information websites that are inclusive and accessible for sexual and/or gender minority people need to show complexity in their portrayals of cancer patients and the kinds of knowledge they might find useful in making cancer health decisions. Transgender and gender nonconforming participants, as well as a significant portion of gender diverse sexual minority participants, showed a high degree of health literacy and media literacy that they used to coordinate various sites of knowledge. These findings suggest that both online engagement and support-in relation to biomedical, biographical, and experiential knowledge-are primary considerations in efforts to address LGBQ/T cancer health disparities. Support targeted specifically to gender minority populations needs to be a key element of health informatics design in order to engage the wider population of $L G B Q / T$ cancer patients.

\section{4. "People Like Me, People Like Us": The Credibility of Online Information, Decision-Making, and Experiential Knowledge}

Participants in the Cancer's Margins research project reported that they often accessed health knowledge online and that they were concerned about the quality of 
that knowledge. Participants expressed concern about the accuracy and credibility of cancer health information that might be available online, and Internet sources were generally regarded with some suspicion concerning credibility.

"You never know what's true and what's not." Debrah (ON, 72, Jewish, lesbian woman, metastatic cervical cancer)

A number of participants brought up the source of the information as a primary part of their concern. Suzette pointed out that the source of the information is directly part of the issue of credibility.

"Anyone can put anything up there. So, you know, how valid is the information? Where is it coming from?" Suzette (NS, 59, Caucasian, lesbian woman, breast cancer)

In order to mitigate the risks of using erroneous knowledge to guide decision-making, Cancer's Margins participants sought out knowledge and networks that were specifically by and for sexual and/or gender minority populations, and prioritized experiential knowledge from other sexual and/or gender minority people diagnosed with cancer.

While many participants reported preferring a faceto-face interaction with other LGBQ/T cancer patients, they were often seeking out peers online because there was a wider community network to connect with other LGBQ/T caner patients online than there was for them locally.

Information and experiential knowledge-sharing was seen as less credible and less relevant to decision-making when it was more general and not specifically geared towards sexual and/or gender minority patients.

"When you know that things like this exist, that there are other people that are living the same thing as we are, people like us." Sylvie (QC, 37, Caucasian, French Canadian, lesbian woman, ovarian cancer)

"When I watched the videos of LGBQ/T cancer patients, it really made me feel better. It was like a breath of fresh air in a period of discouragement. It was really good to see someone who looked a lot more like me." Olivia (QC, 60, Caucasian, lesbian woman, breast cancer)

For LGBQ/T interviewees, the role of sexual and/or gender minority population(s)-specific information was important to provide validation and support for identities, embodiments, and lives that were subjected to the disrepair produced by a diagnosis with cancer.

"I think it's absolutely critical. I'm old school gay, right? I like having our own stuff. I'm not into integration here. I think we're losing-don't even get me started on this. We have already lost so much. I will always fight for separate LGBT stuff. It's critical." Emily (ON, 61, Caucasian, femme, dyke, cervical cancer)

\section{5. "Someone That You Actually Click With": Locating and Facilitating LGBQ/T Community and Network Support}

Given that different types of support are needed by patients undergoing cancer treatment, our findings contribute new knowledge concerning how LGBQ/T cancer patients make extensive use of online tools to counteract the relatively lower levels of support in health decisionmaking that they experience in person. Participants reported that they also went online in order to organize their support: coordinating, scheduling, and delegating support tasks.

\begin{abstract}
"I put an announcement on the website. My partner, a week after my surgery, needed to go to a conference. There's part of me that wanted people to bring me certain things....So I put it online. And people did stuff (in person to support me)." Ninet (BA, 56, Israeli, radical feminist dyke, uterine cancer)
\end{abstract}

Cancer's Margins interviewees who were seeking people similar to themselves went online to connect with other LGBQ/T people and to facilitate interactions that would not be as easily accessed in person. For participants, especially those who were living in smaller or more remote communities, the ability to reach a wider pool of people for various types of support was essential, but they specifically needed to locate other sexual and/or gender minority cancer patients that they could identify and connect with.

"The circle of gay and lesbians is so much smaller in small communities-and having a hard time to find someone that you actually click with in that small community, because you're different. Having cancer on top of that, I wanted to be able to connect with a lesbian who has breast cancer." Marianne (ON, 51, Aboriginal Canadian, gay woman, breast cancer)

By going online to seek out community and network support, participants were able to reach a larger and wider pool of potential interlocutors, and thereby increased the probability of connecting with other LGBQ/T people.

A significant sub-group of participants also noted that they were not able to locate support for their partners and that impeded access to support was an added stress during their cancer treatment. Participants were acutely aware of the impact of their cancer on their partners and support networks. Participants identified support for their partners as being entirely lacking in their experiences online. Partner support was highly prioritized by participants and many participants talked about the 
possibility of their primary support persons getting online support or getting support for their relationships online during treatment.

"What if we did this specifically for lesbians to talk together, especially about how relationships are affected? It could be a chat line.... Often we're left with information that could be shared and typically is not: feelings, tips, medical and psychological decisionmaking, and relationships." Olivia (QC, 60, Caucasian, lesbian woman, breast cancer)

\section{6. "Information That Could Be Shared": Blogging and LGBQ/T Cancer Patients' Contributions to Mobilizing Sexual and/or Gender Minority Knowledge}

Cancer patient blogs contain valuable information about people's cancer experiences and researchers have used blogs by cancer patients as data sources for understanding the role of blogs and communication networks in shaping cancer patients' experiences. Chung and Kim (2008) looked specifically at the impacts of blogging on cancer patients and found that "emotion management" and "information-sharing" were some of the most significant uses of blogging for cancer patients. None of the research available on cancer patients and blogging practices has looked at sexual or gender minority status.

Several Cancer's Margins participants used blogging to communicate their experiences and contribute to the diversity of online cancer knowledge. Participants described using blogs to communicate the process of cancer treatment and decision-making across the cancer trajectory to their extended network group of friends, coworkers, family, community, etc. Blogs were intended to reduce the work carried out by patients in communicating with support networks. Blogs often began as a way to communicate practical support issues with a larger support network and then, in time, provided a highly significant level of emotional and esteem support.

"Would you like to know why I started blogging?.... I realized how hard it was going to be on him, to have to constantly update everybody about everything. And I thought if I blogged then his friends and familyI mean, it really was about him first. They could just go somewhere and see it, and he wouldn't constantly have to ask me what's going on and then distribute it....That's why I started it. And then it turned into the life support thing, life saver, I don't know, rope, this thing that was going to carry me through when I was really upset and I could sit down and write about it." Holly (BA, 44, Jewish, femme, queer bisexual, breast cancer, BRCA1 gene)

Participants also reported that they used blogging to share experiences with others because they felt there was limited information that was specific to them as members of sexual and/or gender minority populations.
Blogs, in this sense, were also seen as a form of service or obligation to other patients to fill in the gaps in cancer information that is available and accessible online for sexual and/or gender minority patients. Blogs allowed participants to create and mobilize experiential cancer knowledge that was specific to them as members of one or more marginalized groups.

"I think my main thing was to provide something for (LGBQ/T) people who ended up in that situation themselves. I couldn't find anything that would tell me what I was about to go through. That's why I decided to put it out there for other (LGBQ/T) people....I wanted (those) people to have some idea what to anticipate." Jake (BC, 52, Caucasian, butch dyke, ovarian cancer, BRCA1 gene)

Blogging afforded participants an online opportunity to mobilize their own "experiential evidence" (Ziebland \& Herxheimer, 2008); that is to say, knowledge that was relevant and specific to their community and support networks. This contribution to knowledge mobilization was taken up by participants as a duty of care to their $\mathrm{LGBQ} / \mathrm{T}$ community so as to refuse the heteronormative and cisnormative narratives of cancer care, and, simultaneously, to create a culturally appropriate emotional support system.

\section{Conclusions}

The Cancer's Margins project advances knowledge concerning how sexual marginality and gender marginality shape access to knowledge and the processes by which marginalized cancer patients engage with knowledge access and mobilization. This analysis advances knowledge about the ways that sexual and/or gender minority cancer patients access knowledge and support and the implications for cancer health decision-making and patientprovider relationships and communication.

Cancer's Margins participants were highly aware of the need to coordinate their online activity with their face-to-face treatment, knowledge, and support networks. The persistent presence of heteronormative and cisnormative narratives in the organization of cancer care knowledge specifically, and health care more generally, put participants in a position where they needed to perform extra work to compensate for the failure of care systems to respond to their cancer health decisionmaking needs. Marginalized patients must do a lot of excess labour to manage and coordinate various fields of knowledge in cancer care environments. Our interviewees shared techniques that they used to navigate cancer knowledge ecologies. They reported that knowledge about cancer and relatedly, decision-making was not designed to meet current standards regarding culturally competent care. The specific techniques that participants used to coordinate knowledge access across diverse locations included: managing disclosure, sorting 
applicable information from cisnormative and heteronormative narratives, and seeking biographical and medical knowledge from other sexual and gender minority cancer patients, in addition to knowledge mobilization techniques such as blogging.

Our analysis provides evidence that $\mathrm{LGBQ} / \mathrm{T}$ cancer patients are making extensive use of online cancer knowledge and support, despite widespread "informational and institutional erasure" (Bauer et al., 2009) of sexual and gender minorities. By going online, participants were able to widen their scope of knowledge access, contribute to $L G B Q / T$-specific knowledge, while increasing the likelihood of finding other LGBQ/T cancer patients with experiential knowledge. To inform their cancer health decision-making and to account for the lack of communication and structural competency in cancer care, LGBQ/T patients sort through biomedical and biographical knowledge that is shaped by heteronormative and cisnormative narratives so as to glean knowledge that aligns with their experiences. Our findings also reflect that $\mathrm{LGBQ} / \mathrm{T}$ cancer patients had an altruistic commitment to knowledge-sharing and mobilization with others in LGBQ/T communities and a robust intersectional lens to shape visions of culturally competent online knowledge-sharing. This analysis also provides evidence that $L G B Q / T$ cancer patients have considerable health literacy and media literacy and use LGBQ/T community networks and experiential knowledge to ameliorate the risks presented by cisnormative and heteronormative health knowledge structures.

We have made an argument for the necessity of undertaking a sexual and gender diversity analysis in both online and face-to-face support programming for sexual and/or gender minority cancer patients. The current organization of cancer knowledge and support spaces excludes sexual and gender minority cancer patients. The strong overall preference expressed by participants for both sexual-minority-specific and gender-minorityspecific online knowledge and support points to particular need for online cancer support that takes into account the unique needs of sexual and gender minority populations. Knowledge and support spaces need to be designed in such a way as to recognize that sexual minority cancer patients and gender minority cancer patients have related, but distinctly different, experiences of cancer health and care.

\section{Acknowledgements}

Research supported by a Canadian Institutes of Health Research Doctoral Award to Mx. Evan Taylor (\#128158), and a ClHR Research Operating Grant awarded to Dr. Mary Bryson (\#275227).

\section{Conflict of Interests}

The authors declare no conflict of interests.

\section{References}

Agénor, M., Bailey, Z., Krieger, N., Austin, S. B., \& Gottlieb, B. R. (2015). Exploring the cervical cancer screening experiences of black lesbian, bisexual, and queer women: The role of patient-provider communication. Women and Health, 55(6), 717-736.

Banerjee, S. C., Walters, C. B., Staley, J. M., Alexander, K., \& Parker, P. A. (2018). Knowledge, beliefs, and communication behavior of oncology healthcare providers (HCPs) regarding lesbian, gay, bisexual, and transgender (LGBT) patient health care. Journal of Health Communication, 23(4), 329-339.

Bauer, G. R., Hammond, R., Travers, R., Kaay, M., Hohenadel, K. M., \& Boyce, M. (2009). "I don't think this is theoretical; this is our lives": How erasure impacts health care for transgender people. The Journal of the Association of Nurses in AIDS Care, 20(5), 348-361.

Boehmer, U., \& Case, P. (2004). Physicians don't ask, sometimes patients tell: Disclosure of sexual orientation among women with breast carcinoma. Cancer, 101(8), 1882-1889.

Boehmer, U., Glickman, M., Winter, M., \& Clark, M. A. (2013). Long-term breast cancer survivors' symptoms and morbidity: Differences by sexual orientation? Journal of Cancer Survivorship, 7(2), 203-210.

Bonevski, B., Randell, M., Paul, C., Chapman, K., Twyman, L., Bryant, J., ... Hughes, C. (2014). Reaching the hardto-reach: A systematic review of strategies for improving health and medical research with socially disadvantaged groups. BMC Medical Research Methodology, 14(42), 1-29.

Bryson, M., \& Stacey, J. (2013). Cancer knowledge in the plural: Queering the biopolitics of narrative and affective mobilities. Journal of Medical Humanities, 34(2), 197-212.

Bryson, M., Taylor, E., Boschman, L., Hart, T., Gahagan, J., Ristock, J., \& Rail, G. (2019). Awkward choreographies from Cancer's Margins: Incommensurabilities of biographical and biomedical knowledge in sexual and/or gender minority cancer patients' treatment. Journal of Medical Humanities, 39(1). https:// doi.org/10.1007/s10912-018-9542-0

Burkhalter, J. E., Margolies, L., Sigurdsson, H. O., Walland, J., Radix, A. E., Rice, D., . . Maingi, S. (2016). The national LGBT cancer action plan: A white paper of the 2014 national summit on cancer in the LGBT communities. LGBT Health, 3(1), 19-31.

Chung, D., \& Kim, S. (2008). Blogging activity among cancer patients and their companions: Uses, gratifications, and predictors of outcomes. Journal of the American Society for Information Science and Technology, 59(2), 297-306.

Diedrich, L. (2007). Treatments: Language, politics, and the culture of illness. Minneapolis, MN: University of Minnesota Press.

Donald, C. A., Dasgupta, S., Metzl, J. M., \& Eckstrand, K. L. (2017). Queer frontiers in medicine: A structural 
competency approach. Academic Medicine, 92(3), 345-350.

Gibson, A., Lee, C., \& Crabb, S. (2016). Representations of women on Australian breast cancer websites: Cultural 'inclusivity' and marginalisation. Journal of Sociology, 52(2), 433-452.

Gibson, A. W., Radix, A. E., Maingi, S., \& Patel, S. (2017). Cancer care in lesbian, gay, bisexual, transgender and queer populations. Future Oncology, 13(15), 1333-1344.

Grabinski, V. F., Myckatyn, T. M., Lee, C. N., PhilpottStreiff, S. E., \& Politi, M. C. (2018). Importance of shared decision-making for vulnerable populations: Examples from postmastectomy breast reconstruction. Health Equity, 2(1), 234-238.

Griggs, J., Maingi, S., Blinder, V., Denduluri, N., Khorana, A. A., Norton, L., . . . Rowland, J. H. (2017). American society of clinical oncology position statement: Strategies for reducing cancer health disparities among sexual and gender minority populations. Journal of Clinical Oncology, 35(19), 2203-2208.

Jabson, J. M., Farmer, G. W., \& Bowen, D. J. (2015). Health behaviors and self-reported health among cancer survivors by sexual orientation. LGBT Health, 2(1), 41-47.

Jabson, J. M., Patterson, J. G., \& Kamen, C. S. (2017). Understanding health information seeking on the internet among sexual minority people: Cross-sectional analysis from the health information national trends survey. JMIR Public Health and Surveillance, 3(2), e39.

Jain, S. (2007). Cancer butch. Cultural Anthropology, 22(4), 501-538.

Kamen, C. S., Smith-Stoner, M., Heckler, C., Flannery, M., \& Margolies, L. (2015). Social support, self-rated health, and lesbian, gay, bisexual, and transgender identity disclosure to cancer care providers. Oncology Nursing Forum, 42(1), 44-51.

Kirby, E., Lwin, Z., Kenny, K., Broom, A., Birman, H., \& Good, P. (2018). "It doesn't exist...": Negotiating palliative care from a culturally and linguistically diverse patient and caregiver perspective. BMC Palliative Care, 17(1), 90-100.

Klawiter, M. (2004). Breast cancer in two regimes: The impact of social movements on illness experiences. Sociology of Health \& IIIness, 26(6), 845-874.

Mason, G. (2001). Body maps: Envisaging homophobia, violence and safety. Social \& Legal Studies, 10(1), 23-44.

Matthews, A. K., Breen, E., \& Kittiteerasack, P. (2018). Social determinants of LGBT cancer health inequities. Seminars in Oncology Nursing, 34(1), 12-20.

Metzl, J. M., \& Hansen, H. (2014). Structural competency: Theorizing a new medical engagement with stigma and inequality. Social Science and Medicine, 103, 126-133.

Meyer, I. H., \& Wilson, P. A. (2009). Sampling lesbian, gay, and bisexual populations. Journal of Counseling Psychology, 56(1), 23-31.

Mol, A. (2002). The body multiple: Ontology in medical practice. Durham \& London: Duke University Press.
Newman, L., Biedrzycki, K., \& Baum, F. (2012). Digital technology use among disadvantaged Australians: Implications for equitable consumer participation in digitally-mediated communication and information exchange with health services. Australian Health Review, 36, 125-129.

Obedin-Maliver, J., Goldsmith, E. S., Stewart, L., White, W., Tran, E., Brenman, S., . . Lunn, M. R. (2011). Lesbian, gay, bisexual, and transgender-related content in undergraduate medical education. Journal of the American Medical Association, 306(9), 971-977.

Orgad, S. (2006). The cultural dimensions of online communication: A study of breast cancer patients' internet spaces. New Media \& Society, 8(6), 877-899.

Peitzmeier, S. M., Reisner, S. L., Harigopal, P., \& Potter, J. (2014). Female-to-male patients have high prevalence of unsatisfactory paps compared to nontransgender females: Implications for cervical cancer screening. Journal of General Internal Medicine, 29(5), 778-784.

Statistics Canada. (2017). Census profile, 2016 Census. Retrieved from https://www12.statcan.gc.ca/censusrecensement/2016/dp-pd/prof/details/page.cfm?Lang =E\&Geo1=PR\&Code1=01\&Geo2=PR\&Code2=01\&Data $=$ Count $\&$ SearchText $=$ canada $\&$ SearchType=Begins $\&$ SearchPR=01\&B1=All\&TABID=1

Sulik, A. (2011). Pink ribbon blues: How breast cancer culture undermines women's health. New York, NY: Oxford University Press.

Tabaac, A. R., Sutter, M. E., Wall, C. S. J., \& Baker, K. E. (2018). Gender identity disparities in cancer screening behaviors. American Journal of Preventive Medicine, 54(3), 1-9.

Tamargo, C. L., Quinn, G. P., Sanchez, J. A., \& Schabath, M. B. (2017). Cancer and the LGBTQ population: Quantitative and qualitative results from an oncology providers' survey on knowledge, attitudes, and practice behaviors. Journal of Clinical Medicine, 6(10), 93.

Tan, S., \& Goonawardene, N. (2017). Internet health information seeking and the patient-physician relationship: A systematic review. Journal of Medical Internet Research, 19(1), 1-17.

Taylor, E., \& Bryson, M. (2016). Cancer's Margins: Trans* and gender nonconforming people's access to knowledge, experiences of cancer health, and decisionmaking. LGBT Health, 3(1), 79-89.

Wald, H. S., Dube, C. E., \& Anthony, D. C. (2007). Untangling the web-The impact of internet use on health care and the physician-patient relationship. Patient Education and Counseling, 68(3), 218-224.

Watters, Y., Harsh, J., \& Corbett, C. (2014). Cancer care for transgender patients: Systematic literature review. International Journal of Transgenderism, 15(3/4), 136-145.

Ziebland, S., \& Herxheimer, A. (2008). How patients' experiences contribute to decision making: Illustrations from DIPEx (personal experiences of health and illness). Journal of Nursing Management, 16(4), 433-439. 


\section{About the Authors}
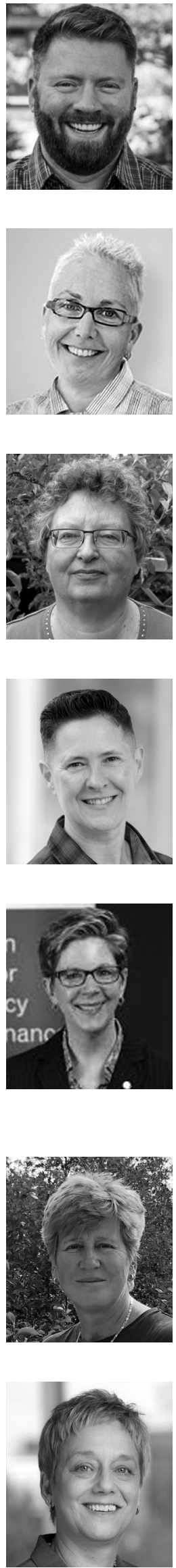

Evan T. Taylor, MSW, RSW is a PhD Candidate in the Faculty of Education at the University of British Columbia, a member of the UBC Public Scholars Network, and a Sessional Instructor at the UBC Social Justice Institute. Evan's doctoral research on the biopolitical intersections of gendered embodiment, knowledge mobility, and health decision-making by sexual and/or gender minority cancer patients was funded by the Canadian Institutes of Health Research. Evan also currently co-leads a CIHR-funded project developing online cancer support resources designed by/for marginalized patients.

Dr. Mary K. Bryson is Senior Associate Dean, Administration, Faculty Affairs and Innovation, and Professor, in the Faculty of Education at the University of British Columbia. A hallmark of the trajectory of their funded research projects is to contribute evidence concerning sexuality and gender, systemic marginalization, and the role of networked social media and information literacies that shape access to knowledge and its mobilization.

Dr. Lorna Boschman is an artist and researcher specializing in arts- and community-based approaches to knowledge translation. She provided project co-ordination for Cancer's Margins and co-led digital storytelling workshops to share LGBT2Q participants' understanding of their cancer diagnosis, treatment, and care. Boschman was the 2016 Vancouver Mayor's Arts Award honoree in Film \& New Media. She recently led a series of community digital storytelling workshops with Vancouver's grunt gallery and is directing a documentary for Canada's OUTtv.

Dr. Tae Hart is Professor of Psychology at Ryerson University. Dr. Hart's research focuses on quality of life, psychological distress, and symptom burden in patients who have been diagnosed with cancer. Dr. Hart also examines the psychological impact of having Lynch syndrome (a genetic mutation that causes hereditary cancers) and factors involved in managing risks associated with Lynch syndrome as well as other familial cancers.

Dr. Jacqueline Gahagan is a Medical Sociologist, a Full Professor in the Faculty of Health at Dalhousie University and holds research scholar positions with the Jean Monnet European Union Centre of Excellence, the Health Law Institute, the Nova Scotia Health Authority, and is a Founding Fellow of the MacEachen Institute. Jacqueline's research focuses on sex and gender-based analyses (SGBA+) in relation to health inequities faced among marginalized populations through the development of effective policy and programming interventions. Prior to joining Dalhousie University, Jacqueline worked in public health at the municipal, provincial and national levels in relation to harm reduction, HIV/HCV prevention, and tobacco use cessation.

Dr. Geneviève Rail is Professor of Feminist Cultural Studies of Health at the Simone de Beauvoir Institute of Concordia University. She is known for her research on women's experiences of body-related institutions (e.g., health systems, pharmaceutical industries, media). Author of over 100 articles or book chapters, she has received funding from SSHRC and CIHR for research involving women from varying sexuality, race, ethnicity, ability, and socioeconomic milieus. She is interested in the intersection and articulation of these women's identifications with the discursive constructions and embodied experiences of the body and health.

Dr. Janice Ristock, FRSC, is Professor of Women's and Gender Studies at the University of Manitoba. Her scholarly work reflects an overarching focus on community well-being and social justice. She has been recognized with many honors and awards, including being elected as a fellow of the Royal Society of Canada, the YWCA/YMCA Woman of Distinction, Canada's Top 100 Most Powerful Women, and a distinguished book award from Division 44 of the American Psychological Association for making a significant contribution to lesbian, gay and bisexual psychology. 